\title{
Information seeking behavior on Facebook: The role of censorship endorsement and personality
}

\author{
Kai Kaspar ${ }^{1} \cdot$ Moritz Müller-Jensen ${ }^{1}$ \\ Published online: 29 June 2019 \\ (C) The Author(s) 2019
}

\begin{abstract}
Facebook started as a platform intended for connecting people but it has developed into a rich information source. Based on the uses-and-gratification approach, we examined to what extent censorship endorsement and personality factors can explain information seeking behavior on Facebook. 1525 German-speaking Facebook users participated in a cross-sectional survey. Censorship endorsement, three personality traits (extraversion, neuroticism, and openness), age, and gender served as predictors in blockwise regression models. Participants' information seeking behavior on Facebook served as the criterion variable, whereby we examined different behavioral strategies. Overall, the extent of one's endorsement of censorship was positively and reliably related to different facets of information seeking. Apparently, censorship might be considered a protection measure to establish a decent communication and information space. In contrast, personality traits were inconsistently related to different facets of information seeking. Extraversion and neuroticism were positively related to information seeking in general, but their impact was absent on some subscales. The effects of age and gender differed from what has been found in previous studies. Overall, the results highlight the necessity of a more differentiated perspective on social media use, provide implications for usesand-gratification research in the context of social media, and indicate interesting venues for future research by incorporating censorship attitude as a hitherto neglected factor.
\end{abstract}

Keywords Uses-and-gratification approach $\cdot$ Information seeking behavior $\cdot$ Facebook $\cdot$ Censorship attitude $\cdot$ Personality traits

\section{Introduction}

Today's digital age is dominated by the Internet and online exchange of information. Social media platforms as well as their users have discovered the potential of using social media, first and foremost Facebook, as an information source. Facebook originally started as a social network intended for connecting people but has developed over the years and made information of any kind accessible. Users can read news and posts about incidents that are happening all over the world. In fact, one of the main motivations of Facebook use is information seeking (Whiting and Williams 2013). The range of available information, although not properly verified in some cases, is huge and the variety of information types offered

Kai Kaspar

kkaspar@uni-koeln.de

1 Department of Psychology, University of Cologne, Richard-Strauss-Str. 2, 50931 Cologne, Germany by Facebook comes along with different forms of users' information seeking strategies (Asghar 2015).

However, while research with a focus on Facebook is generally substantial and has increased exponentially, "research on Facebook as a source of information is still a developing field" and previous studies may "have failed to address the breadth of the construct" (Asghar 2015, p. 261). Specifically, we only have very limited knowledge about how characteristics of the individual Facebook user are related to the different forms of information seeking behavior defined as "the purposive seeking for information as a consequence of a need to satisfy some goal" (Wilson 2000). The uses-and-gratification approach (UGA) provides a fruitful theoretical framework in this context: It emphasizes the active role of the user when it comes to media selection and consumption strategies. Media recipients are assumed to actively link need gratification to media choice. The UGA is not a homogeneous theory but rather a collective term for many theoretical models varying in complexity and conceptual nuances (cf. Rubin 2009; Ruggiero 2000). UGA models usually assume that media recipients have certain psychological and societal needs (and associated motives), eliciting specific expectations about 
how mass media can fulfil these needs and leading to corresponding behavioral patterns of media use in order to obtain the desired gratifications at the end (cf. Katz et al. 1973). Many researchers have already applied the UGA to Facebook use and found that the acquisition of information is one of the primary needs for using Facebook (e.g., Park et al. 2009; Quan-Haase and Young 2010; Urista et al. 2009). Indeed, most previous studies focused on the identification of the main categories of uses and gratifications in the context of Facebook use. Many of those studies applied a combination of qualitative survey techniques and quantitative approaches incorporating a factor analysis to detect main categories (e.g., Joinson 2008; Park et al. 2009; Sheldon 2008). However, it has been noted that uses and corresponding "gratifications are conceptualized and operationalized too broadly (e.g., information-seeking)" (Sundar and Limperos 2013, p. 504 ) and that unidimensional measures of Facebook use "obfuscate motivations for using specific features" (Smock et al. 2011, p. 2322). With respect to information seeking, Whiting and Williams (2013) found in an exploratory study with 25 indepth interviews that $80 \%$ of the respondents reported using social media for very different information seeking purposes, including the search for information about products, social events, business, and educational content. Similarly, Asghar (2015) more recently showed that information seeking on Facebook is a multifaceted concept that covers different behavioral strategies, including social browsing as well as extractive social searching for specific information, but also hedonic stimulation by experiencing fun and entertainment, searching for consumer trend information, and gaining information for meaningful learning. This calls for a more differentiated perspective on how Facebook is used to gratify the need for information. In terms of the UGA, the different forms of information seeking on Facebook represent different behavioral strategies users apply to obtain desired gratifications. In terms of Rayburn and Palmgreen (1984), the different forms of information seeking are the central link between the gratifications sought and the gratifications actually obtained.

In addition to a more specific perspective on the uses and gratifications in the context of social media, some researchers have begun to examine how inter-individual differences in personality and attitudes correlate with uses and gratifications to further deepen our understanding of social media use (e.g., Kircaburun et al. 2018; Lin et al. 2017; Wang et al. 2015). However, Wang et al. concluded that hitherto only "few studies have considered the personal characteristics that may predict the use of social networking sites" (p. 119).

Hence, the present study took a first step to bring these two emerging research lines together by examining how different forms of information seeking behavior on Facebook are related to specific user characteristics.

\section{Facebook Use and Censorship Attitude}

Facebook states its mission is to "give people the power to build community and bring the world closer together" (Facebook 2019). Facebook is a prototypical Web 2.0 application and the most popular social networking site (SNS) enabling users to collaborate by creating and sharing information. This mission cannot be fulfilled in several countries as access to Facebook is completely banned or strictly censored. How or to what extent Facebook is responsible for its own censorship remains controversial. However, Facebook is often seen as a space of relatively uncensored information, in particular in countries where internet content is (partially) censored (e.g., Warren et al. 2016). Internet content is censored in more than 30 countries, but social media platforms might allow more information transparency (Bertot et al. 2010). In this context, $\mathrm{Ng}$ et al. (2019) recently found cultural differences in psychological reactance to social media censorship. Iranian Canadians were found to exhibit state reactance to a higher degree compared to European and Asian Canadians, when the government (fictitiously) promoted social media censorship. Thereby, the effect of culture on psychological reactance was mediated by previous censorship experience, which was higher in Iranian Canadians.

Substantial internet censorship seems to exist also in China (cf. Bamman et al. 2012). Accordingly, UGA research has found that getting access to information is a central motivation for Chinese users to bypass internet censorship with appropriate software, while bypassing behavior was more likely when users reported a negative attitude toward censorship (Yang and Liu 2014). Nonetheless, Kou et al. (2017) found seemingly contradictory attitudes and practices among Chinese participants, as "they showed proficiency at bypassing censorship, but were sometimes comfortable with censored information. They were willing to share sensitive information with others, but saw the benefits of limiting the public's access to information under certain circumstances" (p. 377), for example, with respect to online hate speech or fake news distributed through SNS. Apparently, Facebook users' attitude toward censorship contributes to their motivation for using Facebook as an information source, but internet users' do not completely refuse censorship under all circumstances. This effect may not be limited to countries where internet content is substantially censored by governmental institutions.

In fact, research indicates that censorship is a global phenomenon in social media, at least with respect to self-censorship: Madsen and Verhoeven (2016) found that coworkers of a Danish bank did not only censor themselves by withdrawing, "but they also postpone publishing content, phrase or frame content differently, imagine responses from organizational members, ask others for a second opinion, choose another channel, or write only positive comments" (p. 387). Additionally, Das and Kramer (2013) as well as Sleeper 
et al. (2013) found that Facebook users from the U.S. tend to censor more when their audience is harder to define and they are not able to exactly target their desired audiences with the tools provided by Facebook. Kwon et al. (2015) examined U.S. college students and revealed that the exposure to diverse opinions on Facebook was positively associated with the tendency to self-censor political expression. Correspondingly, Hoffmann and Lutz (2017) surveyed Facebook users in Germany and found that network heterogeneity increased the perception of the opinion climate as adverse, leading to more self-censorship. Interestingly, a survey among 194 German parliamentarians by Dohle and Bernhard (2014) revealed that "the more politicians assumed the public was highly susceptible to political influence through online media, the more they supported censorship measures" (p. 263), supporting the notion that censorship is considered an appropriate measure to regulate mass media even by German politicians. These results raise the question how censorship attitude of Facebook users and information seeking behavior on Facebook are related in countries that are not suspected of having established governmental censorship. The present study aimed to shed first light on this topic.

Importantly, censorship can aim at very different domains (including, but not limited to, written materials, music, political activities, and art), different content (e.g., political statements, pornography, and sexuality), different media (e.g., books, television, and internet), or even specific providers of information within a medium (e.g., Facebook, Google, and online magazines). Following Hense and Wright (1992), we conceptualized participants' attitude toward censorship in a relatively broad sense in the present study, that is, as a general attitude toward the "freedom of speech and expression" (p. 1666) in media and public being not limited to specific domains, content, media, or content providers. We aimed to answer whether people who are inclined to use Facebook as an information source would be more likely to approve or disapprove of censorship. Given the research presented above, both ways seem reasonable as censorship can be seen as a doubleedged sword - it may hinder media users' online freedom but it may also help in some instances (Kou et al. 2017):

On the one hand, censorship basically violates freedom of speech and expression and it may also counteract the overall spirit of the Web 2.0 as an environment of interpersonal information exchange that is not monitored and censored by national institutions on the basis of government policy (cf. Bertot et al. 2010). Over the years, SNS have become an essential forum for public discourse. Facebook members use their network as a tool and may not want to be restricted in doing so. Filtering information may trigger users' opinion that basic principles of democracy in the communication process are threatened. Hence, people's information seeking behavior on
Facebook might be negatively correlated with censorship endorsement.

On the other hand, censorship may serve as a protection mechanism given there are several types of problematic online content, such as pornography, violence, and hate speech, which is easy to access and can have a very negative influence on users, in particular on children. Thus, a certain amount of censorship may be considered necessary to maintain the atmosphere that attracts users to SNS in the first place (cf. Kou et al. 2017). Moreover, internet content should always be judged with caution as it can easily be distorted and manipulated, manifesting in fake news. As a consequence, information seekers on Facebook might endorse censorship to some extent in favor of a "decent" communication and information space.

In a nutshell, both pro- and anti-censorship attitudes can be associated with information seeking behavior on Facebook. We hence examined the following hypothesis:

H1: There is a significant relation between participants' censorship endorsement and their degree of information seeking on Facebook.

\section{Facebook Use and Personality Traits}

Research focusing on the relationship between personality traits and Facebook use is continuously expanding in order to better understand who uses Facebook as an information source (e.g., Chen 2014; Kuo and Tang 2014). In terms of the UGA, individuals' motivation to search for specific information on SNS is driven by their needs. Although some theorists draw a sharp demarcation between traits and needs, operationalizations of needs and traits show a remarkable overlap on the empirical level, coining the term of "motivational traits" (Costa Jr. and McCrae 1988). In this sense, it seems reasonable to examine the relation between relatively time-independent personality traits and information seeking on Facebook, as they have already been found to influence Facebook use in general (e.g., Chen 2014; Kuo and Tang 2014). In this context, the traits extraversion, neuroticism, and openness to new experiences showed some correlations with Facebook use:

The trait extraversion, which generally refers to people who enter more social situations and have larger social networks (Feiler and Kleinbaum 2015), seems to be positively correlated with the frequency of Facebook use and the level of Facebook activity (Gosling et al. 2011). Similarly, Quercia and colleagues (Quercia et al. 2012) observed a positive correlation between extraversion and the number of Facebook friends. Kuo and Tang (2014) found more Facebook use in highly extraverted users. Hence, extraversion seems to predict higher Facebook use in general, but it has not yet been 
specifically associated with the different forms of information seeking behavior on Facebook examined here. We tested the following hypothesis:

H2a: Extraversion is positively related to information seeking behavior on Facebook.

The trait openness to new experiences is characterized by creativity, intellectualism, and preference for novelty (Seidman 2013). It was found to predict more activity on Facebook (Skues et al. 2012). High openness was also associated with more intense Facebook use (Kuo and Tang 2014). Individuals who score high on openness may be particularly inclined to explore the variety of information offered by Facebook due to their broader range of interests. Facebook's diverse information content and features allow them to pursue those interests by corresponding information seeking. Hence, we hypothesized:

H2b: Openness is positively related to information seeking behavior on Facebook.

The trait neuroticism is linked to emotional liability, anxiety, fear, impulsiveness, and more negative mood states (Quercia et al. 2012). In a study by Halder et al. (2017), neuroticism negatively correlated with numerous facets of students' (offline) information seeking in the context of learning in a higher education institution. However, information seeking was conceptualized in more general terms and was not tailored to online behavior. The authors therefore speculated that "neurotic tendencies of an individual may act as an obstacle to successful information seeking", because highly neurotic people may be vulnerable to negative emotions blocking their way to seek, whereas people low in neuroticism are able to resolve obstacles coming in their information seeking process (p. 48). In contrast, and with respect to Facebook use, high scores on neuroticism were paralleled by disclosure of more personal information and longer posts (Shen et al. 2015). Seidman (2013), who found a positive correlation between neuroticism and seeking information about other people on Facebook, suggested that neurotic people might try to solve their social difficulties online, especially as "Facebook represents a safe place" (p. 404). Consequently, Facebook may provide a communication and information environment that stimulates highly neurotic people to dip into interpersonal information exchange more actively than in offline and face-toface environments. We thus hypothesized:

H2c: Neuroticism is positively related to information seeking behavior on Facebook.

Importantly, besides the outlined relationships between personality traits and Facebook use, few studies have examined correlations between censorship attitude and the said personality traits: In one exemplary study, Lambe (2004) did not find a correlation between extraversion and the degree to which people endorse censorship of different content. However, censorship endorsement was negatively correlated with openness, whereas it showed a positive correlation with neuroticism. Consequently, we examined the relation between information seeking on Facebook and censorship endorsement while controlling for these personality traits and vice versa.

Beyond personality traits, research indicated that females are more likely to engage in information seeking on Facebook than males (Seidman 2013). Also, research revealed reliable age effects: Although the number of older people using Facebook is growing, younger users are more active and have more contacts (Hayes et al. 2015; Quercia et al. 2012). Thus, we considered these two factors in our study but without formulating specific hypotheses regarding information seeking behavior.

\section{Method}

\section{Participants and Procedure}

A sample of 1525 German-speaking participants (1140 females; $M_{\text {age }}=30.00, S D_{\text {age }}=10.48$ ) provided a full dataset and were included in the statistical analyses. Participants had to be at least 18 years old and required a Facebook account. Participants who were underage $(n=28)$ were excluded, as well as the upper $1 \%$ of the age distribution (age $>64, n=15$ ) due to some implausible high values and to avoid biases in the regression analyses. We recruited the participants by means of a combination of convenience sampling and snowball sampling. That is, Facebook users were contacted via university mailing lists and asked to participate in the study as well as to distribute the link to their Facebook friends and ask them to further distribute the link. No personal data was collected other than the demographics of age and gender to retain participants' anonymity. After clicking on the link to open the study, we informed the participants that they can stop the study whenever they want and that completion of the survey is considered to indicate informed consent. Participants initially provided their age and gender, then they reported the amount of time spent on Facebook and the number of their Facebook friends. Afterwards, participants filled out three questionnaires in randomized order, covering information seeking behavior on Facebook, censorship endorsement, and personality traits. 


\section{Measurements}

The Information Seeking on Facebook Scale (ISFS) The original ISFS includes 23 5-point Likert items ( $1=$ strongly disagree, $5=$ strongly agree), "reflecting core information seeking strategies" (Asghar 2015, p. 262). The final ISFS scale (21 items) provides a global score $(\alpha=.84)$ and five subscales: Extractive Social Searching for specific information (e.g., "The exchange of information offered through Facebook allows me to answer personal issues effectively", $\alpha=.65$ ), explorative Social Browsing (e.g., "In general, I read news, scientific facts or inspirational quotes shared on Facebook because I find them informative", $\alpha=.74)$, Hedonic Proclivity (e.g., "Reading Facebook newsfeed is entertaining", $\alpha=.74$ ), searching for Consumer Trends Information (e.g., "I use Facebook to follow new trends", $\alpha=.62$ ), and gaining information for meaningful learning, General Erudition (e.g., "Facebook makes me learn about a topic I am not familiar with", $\alpha=.69$ ). A German version of the ISFS was rigorously constructed by means of translation-back-translation methodology.

Attitude toward Censorship Questionnaire Previous research on censorship attitude either used open-ended interviews (e.g., Kou et al. 2017), partially outdated instruments without any reference to the Internet (e.g., Hense and Wright 1992; Rojas et al. 1996), or specific construct operationalizations being not appropriate for the purpose of the present study (e.g., Lambe 2002). Therefore, we firstly adapted seven items $(\alpha=.76)$ from the Hense and Wright (1992) which can be considered as still contemporary: "Music, books, movies, and video games containing unpopular political viewpoints should not be sold", "Music, books, movies, and video games with obscene and offensive content should be removed from the shelves of public libraries", "Demonstrations/rallies by unpopular political groups should be prohibited", "Music, books, movies, and video games which are offensive to individuals' religious beliefs should be banned", "Homosexual relationships should not be depicted in media", "Art exhibits which contain sacrilegious images or symbols should not be displayed by museums", and "All individuals should have the right to express their ideas, no matter how unpopular or controversial they might be" (reversed coding). Second, we added three new items explicitly addressing the Internet $(\alpha=.75)$ : "State courts should be able to ban the access to any webpage that contains inappropriate information", "Censorship boards should have the power to ban dangerous webpages", and "I support governmental control over the internet". We had a closer look at this subscale in the context of the analyses. Higher values on the 5 -point scale ( $1=$ strongly disagree; $5=$ strongly agree $)$ indicated a stronger censorship endorsement.
The Big Five Inventory (BFI-10) The BFI-10 is a 10-item short version of the Big Five Inventory that predicts almost $70 \%$ of the variance of the full scales. It is suitable for online studies with limited time constraints (Rammstedt and John 2007). Each personality trait is measured by two 5-point Likert items ( 1 = disagree strongly, 5 = agree strongly). Our focus was limited to extraversion $(\alpha=.73)$, neuroticism $(\alpha=.62)$, and openness $(\alpha=.48)$, whereby the internal consistency of the latter was low.

Validity Items Information seeking on Facebook is supposed to correlate with the time spent on Facebook and with the number of Facebook friends (Asghar 2015). To assess construct validity, participants reported the amount of time daily spent on Facebook (0-14 min: $n=168 ; 15-29 \min .: ~ n=333$; 30-44 min.: $n=358 ; 45-59$ min.: $n=267$; 60 and more min.: $n=399)$ and the number of their Facebook friends $(M=$ 298.95, $S D=274.37$ ).

\section{Data Analysis}

First, we ran a reliability analysis in order to identify problematic items of the ISFS on the basis of corrected item-total correlations, as Asghar (2015) found two items which were not appropriate and hence excluded from the original 23-item scale.

Second, we computed correlations between the ISFS total score and the validity items (time daily spent on Facebook and number of Facebook friends) as well as between all subscales of the ISFS to assess construct validity.

Third, we ran blockwise regression analyses, including an outlier analysis by means of Cook's distance. The ISFS total score and the subscales served as criterion variables in the regression models. Participants' gender and age (block 1), censorship endorsement (block 2), and the personality traits extraversion, neuroticism, and openness (block 3) served as predictor variables.

Finally, we re-ran all blockwise regression analyses and substituted the general censorship endorsement score (mean across all ten items, $\alpha=.82$ ) by a reduced scale that was limited to the three items which specifically measured censorship of the Internet, in order to check whether this narrower focus would change the predictive power of the construct.

\section{Results}

Congruent with Asghar's (2015) findings, the two items "I do not read quotes shared through Facebook's photos or statuses" and "For me, reading Facebook posts is a waste of time" showed (corrected) negative item-total correlations ( -.24 and -.43 ) and were dropped from the analysis. The ISFS total score was positively correlated with the amount of time daily 
spent on Facebook (Spearman rank correlation $r_{S}=.31$, $p<.001)$ and the number of Facebook friends $\left(r_{S}=.12\right.$, $p<.001)$, indicating some construct validity. The subscales of the ISFS were weakly to moderately positively correlated and showed strong positive correlations with the ISFS total score (see Table 1).

In the next step, we computed blockwise regression models. The ISFS total score and the subscales served as criterion variables, participants' gender and age (block 1), censorship endorsement (block 2), and the personality traits (block 3) served as predictor variables. The preceding outlier analysis by means of Cook's distance aimed at the identification of cases with values larger than 1 which are considered to possibly bias the results. The highest value observed was 0.016. Consequently, no outlier was present and biased the results. Table 1 presents the complete inter-correlation matrix of the criterion and predictor variables. In general, female participants scored higher on all personality traits and showed a stronger censorship endorsement. Correlations between personality traits were weak.

Our initial regression analysis focused on the ISFS total score (Table 2): Regarding H1, the blockwise regression revealed a positive relation between participants' censorship endorsement and the amount of information seeking behavior on Facebook. Also, extraversion and neuroticism were positively related to the ISFS total score, supporting $\mathrm{H} 2 \mathrm{a}$ and $\mathrm{H} 2 \mathrm{c}$. Contradicting $\mathrm{H} 2 \mathrm{~b}$, openness was not related to the ISFS total score. Finally, age was positively related to the ISFS total score, whereas gender was not (apart from a significant bivariate correlation).

With respect to social searching (see Table 2), male participants showed higher scores. Age and censorship endorsement were positively related to the amount of social searching. Personality traits increased the explained variance in social searching only weakly, as neuroticism and openness had a marginally significant beta weight. In contrast, the extent of hedonic proclivity (see Table 2) was higher in female participants and positively related to censorship endorsement and extraversion. Age and the extent of openness received only a marginally significant beta weight.

As shown in Table 3, things were different with respect to the extent of social browsing: Age and openness showed a positive relation to social browsing, whereas the impact of gender was less pronounced. Importantly, the impact of censorship endorsement was negative and only marginally significant this time. In contrast, censorship endorsement was

Table 1 Descriptive statistics, Cronbach's $\alpha$, and bivariate correlations among criterion and predictor variables of the regression models

\begin{tabular}{|c|c|c|c|c|c|c|c|c|c|c|c|c|c|c|c|}
\hline & \multirow[t]{2}{*}{$M$} & \multirow[t]{2}{*}{$S D$} & \multirow[t]{2}{*}{$\alpha$} & \multicolumn{12}{|c|}{ Correlations } \\
\hline & & & & 1. & 2. & 3. & 4. & 5. & 6. & 7. & 8. & 9. & 10. & 11. & 12 . \\
\hline \multicolumn{16}{|l|}{ Criterion variables } \\
\hline 1. ISFS total score & 2.91 & 0.55 & .84 & & & & & & & & & & & & \\
\hline $\begin{array}{l}\text { 2. Social } \\
\text { Searching }\end{array}$ & 2.28 & 0.79 & .65 & $.65 * * *$ & & & & & & & & & & & \\
\hline $\begin{array}{l}\text { 3. Hedonic } \\
\text { Proclivity }\end{array}$ & 3.55 & 7.12 & .74 & $.64 * * *$ & $.26 * * *$ & & & & & & & & & & \\
\hline 4. Social Browsing & 3.32 & 8.18 & .74 & $.72 * * *$ & $.28 * * *$ & $.32 * * *$ & & & & & & & & & \\
\hline $\begin{array}{l}\text { 5. Consumer } \\
\text { Trends } \\
\text { Information }\end{array}$ & 2.44 & 0.79 & .62 & $.68 * * *$ & $.29 * * *$ & $.30 * * *$ & $.30 * * *$ & & & & & & & & \\
\hline $\begin{array}{l}\text { 6. General } \\
\text { Erudition }\end{array}$ & 3.09 & 0.77 & .69 & $.83 * * *$ & $.49 * * *$ & $.48 * * *$ & $.64 * * *$ & $.37 * * *$ & & & & & & & \\
\hline \multicolumn{16}{|l|}{ Predictor variables } \\
\hline $\begin{array}{l}\text { 7. Gender: } \\
0=\text { male } \\
1=\text { female }\end{array}$ & - & - & - & $.07 * *$ & -.02 & $.13 * * *$ & $.05^{*}$ & .02 & $.07 * *$ & & & & & & \\
\hline 8. Age & 30.00 & 10.48 & - & $.11 * * *$ & $.16^{* * * *}$ & $.06^{*}$ & $.08 * *$ & -.02 & $.14 * * *$ & .03 & & & & & \\
\hline $\begin{array}{l}\text { 9. Censorship } \\
\text { endorsement: } \\
\text { General }\end{array}$ & 2.54 & 0.75 & .82 & $.12 * * *$ & $.12 * * *$ & $.13 * * *$ & -.03 & $.09^{* * * *}$ & $.10 * * *$ & $.25 * * *$ & $.19 * * *$ & & & & \\
\hline $\begin{array}{l}\text { 10. Censorship } \\
\text { endorsement: } \\
\text { Internet }\end{array}$ & 3.00 & 1.03 & .75 & $.09 * * *$ & $.07 * *$ & $.14 * * *$ & .01 & $.04^{+}$ & $.09 * * *$ & $.23 * * *$ & $.11 * * *$ & $.81 * * *$ & & & \\
\hline 11. Extraversion & 3.51 & 0.97 & .73 & $.06^{*}$ & -.002 & $.07 * *$ & .04 & $.05 *$ & .04 & $.08 * *$ & $.07 * *$ & $.08 * *$ & $.09 * * *$ & & \\
\hline 12. Neuroticism & 2.71 & 0.95 & .62 & $.05^{+}$ & .02 & .03 & .01 & $.08 * *$ & .02 & $.19 * * *$ & $-.16^{* * *}$ & .04 & .03 & $-.28 * * *$ & \\
\hline 13. Openness & 3.66 & 0.91 & .48 & .01 & .02 & $-.05^{+}$ & $.09^{* * *}$ & $-.05^{+}$ & .03 & $.08 * *$ & -.01 & $-.16 * * *$ & $-.11 * * *$ & $.10 * * *$ & -.001 \\
\hline
\end{tabular}


Table 2 Results of regressions: ISFS total score, social searching, and hedonic proclivity

\begin{tabular}{|c|c|c|c|c|c|c|c|c|c|c|c|c|}
\hline & \multicolumn{4}{|c|}{ ISFS Total Score } & \multicolumn{4}{|c|}{ Social Searching } & \multicolumn{4}{|c|}{ Hedonic Proclivity } \\
\hline & \multicolumn{3}{|c|}{$\begin{array}{l}\text { Censorship endorsement } \\
\text { (CE): General }\end{array}$} & \multirow{2}{*}{$\begin{array}{l}\text { CE: Internet } \\
\beta\end{array}$} & \multicolumn{3}{|c|}{ CE: General } & \multirow{2}{*}{$\begin{array}{l}\text { CE: Internet } \\
\beta\end{array}$} & \multicolumn{3}{|c|}{ CE: General } & \multirow{2}{*}{$\begin{array}{l}\text { CE: Internet } \\
\beta\end{array}$} \\
\hline & $\beta$ & $\beta$ & $\beta$ & & $\beta$ & $\beta$ & $\beta$ & & $\beta$ & $\beta$ & $\beta$ & \\
\hline \multicolumn{13}{|l|}{ Block 1} \\
\hline $\begin{array}{l}\text { Gender } \\
\qquad(0=\text { male } \\
1=\text { female })\end{array}$ & $.06^{*}$ & .04 & .02 & .03 & -.03 & $-.05^{*}$ & $-.07 *$ & $-.05^{+}$ & $.13 * * *$ & $.11 * * *$ & $.10 * * *$ & $.10 * * *$ \\
\hline Age & $.11 * * *$ & $.10 * * *$ & $.10 * * *$ & $.11 * * *$ & $.16^{* * *}$ & $.14 * * *$ & $.15 * * *$ & $.16^{* * *}$ & $.06^{*}$ & .04 & $.04^{+}$ & $.05^{+}$ \\
\hline \multicolumn{13}{|l|}{ Block 2} \\
\hline $\begin{array}{l}\text { Censorship } \\
\text { endorsement }\end{array}$ & & $.09 * *$ & $.09 * *$ & $.07 * *$ & & $.11 * * *$ & $.12 * * *$ & $.07 *$ & & $.10 * * *$ & $.09 * *$ & $.10 * * *$ \\
\hline \multicolumn{13}{|l|}{ Block 3} \\
\hline Extraversion & & & $.06^{*}$ & $.06^{*}$ & & & -.01 & -.01 & & & $.07 * *$ & $.07 *$ \\
\hline Neuroticism & & & $.08^{* *}$ & $.08 * *$ & & & $.05^{+}$ & $.05^{+}$ & & & .04 & .04 \\
\hline Openness & & & .02 & .01 & & & $.05^{+}$ & .04 & & & $-.05^{+}$ & $-.05^{+}$ \\
\hline$R^{2}:$ & $.017 * * *$ & $.023 * * *$ & $.030 * * *$ & $.028 * * *$ & $.026^{* * *}$ & $.037 * * *$ & $.041 * * *$ & $.033 * * *$ & $.021 * * *$ & $.029 * * *$ & $.035 * * *$ & $.039 * * *$ \\
\hline$\Delta R^{2}$ & $.017 * * *$ & $.007 * *$ & $.007 *$ & & $.026 * * *$ & $.011 * * *$ & $.004^{+}$ & & $.021 * * *$ & $.009 * * *$ & $.006^{*}$ & \\
\hline
\end{tabular}

$* * * p<.001, * * p<.01, * p<.05,{ }^{+} p<.10$

significantly positively related to the extent of searching for consumer trends information and the extent of general erudition (see Table 3 ). The former was also positively correlated with extraversion and neuroticism, the latter was positively correlated with age.

All in all, participants' gender and age showed inconsistent effects across different facets of information seeking behavior on Facebook, while age showed the highest beta weights in most cases. The extent of censorship endorsement was positively related to all facets of information seeking (except social browsing). The addition of personality traits to the regression models increased the amount of explained variance in most cases, but the effect of extraversion, neuroticism, and openness depended on the facet of information seeking behavior.

Table 3 Results of regressions: social browsing, consumer trends information, and general erudition

\begin{tabular}{|c|c|c|c|c|c|c|c|c|c|c|c|c|}
\hline & \multicolumn{4}{|c|}{ Social Browsing } & \multicolumn{4}{|c|}{ Consumer Trends Information } & \multicolumn{4}{|c|}{ General Erudition } \\
\hline & \multicolumn{3}{|c|}{$\begin{array}{l}\text { Censorship endorsement } \\
\text { (CE): General }\end{array}$} & \multirow{2}{*}{$\begin{array}{l}\text { CE: Internet } \\
\beta\end{array}$} & \multicolumn{3}{|c|}{ CE: General } & \multirow{2}{*}{$\begin{array}{l}\text { CE: Internet } \\
\beta\end{array}$} & \multicolumn{3}{|c|}{ CE: General } & \multirow{2}{*}{$\begin{array}{l}\text { CE: Internet } \\
\beta\end{array}$} \\
\hline & $\beta$ & $\beta$ & $\beta$ & & $\beta$ & $\beta$ & $\beta$ & & $\beta$ & $\beta$ & $\beta$ & \\
\hline \multicolumn{13}{|l|}{ Block 1} \\
\hline $\begin{array}{l}\text { Gender } \\
\qquad(0=\text { male } \\
1=\text { female })\end{array}$ & $.05^{+}$ & $.06^{*}$ & $.05^{+}$ & .04 & .02 & -.01 & -.03 & -.01 & $.06^{*}$ & $.05^{+}$ & .03 & .04 \\
\hline Age & $.08 * *$ & $.09 * * *$ & $.09 * * *$ & $.08 * *$ & -.02 & -.04 & -.03 & -.02 & $.14 * * *$ & $.13 * * *$ & $.14 * * *$ & $.14 * * *$ \\
\hline \multicolumn{13}{|l|}{ Block 2} \\
\hline $\begin{array}{l}\text { Censorship } \\
\text { endorsement }\end{array}$ & & $-.06^{*}$ & $-.05^{+}$ & -.01 & & $.10 * * *$ & $.09 * *$ & .03 & & $.06^{*}$ & $.06^{*}$ & $.06^{*}$ \\
\hline \multicolumn{13}{|l|}{ Block 3} \\
\hline Extraversion & & & .03 & .03 & & & $.08 * *$ & $.09 * *$ & & & .03 & .03 \\
\hline Neuroticism & & & .02 & .02 & & & $.10 * * *$ & $.11 * * *$ & & & $.05^{+}$ & $.05^{+}$ \\
\hline Openness & & & $.07 * *$ & $.08 * *$ & & & -.04 & $-.05^{+}$ & & & .04 & .03 \\
\hline$R^{2}:$ & $.008 * *$ & $.012 * * *$ & $.019 * * *$ & $.016 * * *$ & .001 & $.010 * *$ & $.022 * * *$ & $.017 * * *$ & $.025 * * *$ & $.028 * * *$ & $.031 * * *$ & $.031 * * *$ \\
\hline$\Delta R^{2}:$ & $.008^{* *}$ & $.004 *$ & $.007^{*}$ & & .001 & $.009 * * *$ & $.012 * * *$ & & $.025 * * *$ & $.003 *$ & .004 & \\
\hline
\end{tabular}

$* * * p<.001, * * p<.01, * p<.05,{ }^{+} p<.10$ 
With respect to the ISFS total score, extraversion and neuroticism showed a significant positive relation. Importantly, the result pattern across all information seeking scales was remarkably stable when substituting the general censorship endorsement by a reduced scale limited to the items which solely addressed censorship of the Internet, except a diminishing effect regarding searching for consumer trends information.

\section{Discussion}

Given that Facebook has evolved into a comprehensive information source, we examined to what extent censorship endorsement and personality factors can explain different forms of information seeking behavior on Facebook.

We found that censorship endorsement was positively and (except social browsing) reliably related to the different forms of information seeking (H1). Individuals who endorse censorship might be especially prone to use Facebook as an information source, as Facebook allows them to self-censor their profile content via self-selected friends, groups, and "likes". Apparently, censorship seems to be considered a protection measure in favor of a decent communication and information space. This novel result is promising but also in need of further clarification. On the one hand, censorship can basically affect various forms of information (processes), including hate speech, pornographic material, and information automatically created by bots. In this sense, censorship attitude can be directed toward very different things. Future studies should further disentangle this aspect. The present study indicates that people's general censorship attitude (including the internet, books, movies, music, video games, demonstrations, and art exhibitions) is not completely different from people's attitude limited to internet censorship. On the other hand, the question arises what organization or governmental institution is considered trustworthy and capable enough to perform appropriate information filtering.

Besides the robust effect of censorship endorsement, personality traits showed inconsistent relations to facets of information seeking on Facebook (H2). Extraversion and neuroticism were positively related to information seeking behavior in general, but a significant relation to information seeking was absent on some subscales. The positive effect of extraversion supports previous studies showing that highly extraverted individuals enter more social situations and have larger social networks (Feiler and Kleinbaum 2015), use Facebook more frequently and actively (Gosling et al. 2011), and have to manage more content provided by more Facebook friends (Quercia et al. 2012). Indeed, we observed a positive correlation between extraversion and the number of Facebook friends, $r_{S}=.19, p<.001$. Regarding the subscales, extraversion was particularly strongly associated with hedonic proclivity and searching for consumer trends information. These results correspond with observations that extraversion is positively associated with hedonic motivation (Tsao and Chang 2010) and - mediated through hedonic value - with brand affect (Matzler et al. 2006). The stronger perceptions of affective stimuli by extraverted individuals (cf. Lucas et al. 2008) might explain why they are more prone to actively search for information gratifying their needs. The positive relation between neuroticism and information seeking suggests that highly neurotic people actually prefer to solve their social difficulties online (Seidman 2013). This result complements the finding that highly neurotic individuals disclose more personal information and provide longer posts on Facebook (Shen et al. 2015). In contrast, openness did not correlate with information seeking on Facebook in general but it was positively associated with explorative social browsing. This result corresponds to the observation that openness is positively associated with internet use (Tuten and Bosnjak 2001). However, the present result contradicts more recent findings showing no correlation between openness and the (unspecific) use of SNS (e.g., Skues et al. 2012; Wilson et al. 2010). Wilson et al. (2010) concluded: "It may be that SNS may no longer be as 'new' an experience for some young people, so has lost some of its appeal for those eager to experience even newer activities" (p. 175). Yet, the present results do not support this conclusion. Given that the effect of openness was inconsistent across the ISFS subscales, we may conclude that inferences limited to a global perspective on SNS are inappropriate. Instead, we suggest to explicitly consider different facets of information seeking behavior.

Finally, the effects of age and gender were different from previous findings: Seidman (2013) found that females were more engaged in information seeking on Facebook than males. We also observed higher ISFS total scores for females as well as higher scores regarding hedonic proclivity, social browsing, and general erudition (bivariate correlations, see Table 1). However, when additionally including participants' censorship endorsement and personality traits into the regression models, the effect of gender was generally reduced and no longer significant, except for hedonic proclivity. Moreover, the non-significant bivariate correlation between gender and the extent of social searching changed into a significant relation, whereby men reported a stronger tendency for social searching. This result pattern highlights the necessity of a more differentiated perspective on information seeking on SNS. In contrast, we found a relatively stable positive relation between participants' age and facets of information seeking. This result is an interesting complement to previous findings according to which younger Facebook users are more active and have more contacts (Hayes et al. 2015; Quercia et al. 2012). When focusing on information seeking, older users are seemingly more engaged, reflecting age-related differences in media selection and media use. 


\section{Implications for UGA and Facebook Research}

The present results have some important implications for future research focusing on the UGA and Facebook.

In accordance with other researchers who criticized the width and sometime vagueness of uses and gratification categories (e.g., Asghar 2015; Smock et al. 2011; Sundar and Limperos 2013), we want to point out that information seeking on Facebook should be understood as a multifaceted concept covering very different behavioral strategies. In general, a more differentiated perspective on SNS use allows deeper insights into the behavioral strategies applied to gratify specific needs. With respect to Facebook, such a perspective appears to be mandatory because the range of SNS becomes successively more diverse and specific user groups prefer specific SNS due to the platforms' disparate or unique features. It is conceivable that Facebook will become a platform primarily used to gratify specific facets of the need for information that is related to one's already established social network with close others, whereas other platforms will be preferred for self-disclosure, expanding one's own social network, and distributing information to the public (cf. Shane-Simpson et al. 2018).

Additionally, the present study highlights the importance of personality traits and censorship attitude in the context of UGA. Uses-and-gratification models basically assume that media recipients have certain needs which elicit specific expectations about how mass media can fulfill these needs, leading to specific behavioral patterns of media use in order to obtain the desired gratifications (cf. Katz et al. 1973). Personality traits and censorship attitude presumably shape users' expectations about how well a specific SNS can gratify one's needs, and factual censorship of SNS sets specific constraints for media use and need gratification. Future studies may scrutinize how personality and censorship attitude specifically affect users' expectations about need gratification through SNS, depending on the degree of factual censorship.

Moreover, we want to highlight (once more) a central question that conceptually and methodologically challenges the UGA: Which specific needs are the driving force behind specific behavioral strategies applied to get specific gratifications? The present study puts different behavioral strategies, which link the gratifications sought and the perceived gratifications obtained (Rayburn and Palmgreen 1984), into the focus of research. However, what still remains unclear is how users translate their needs, expectations about mass media, and associated motives into specific behavioral strategies. With reference to Katz et al. (1973) who already outlined two ways how to examine the relation between needs and gratifications, we suggest to start with the observable behavior and associated gratifications obtained in order to infer the underlying needs, instead of starting with a catalogue of more or less generic needs that are translated into behavioral strategies targeting specific gratifications. The advantage of the former way is that at least the true media consumption process can be captured (even if the subsequent inference of needs is false). In contrast, the latter way may lead to behavioral strategies that are not existent in real life, and it also entails the risk of a false catalogue of needs due to their difficult accessibility in general.

Finally, censorship attitude has been mainly examined with respect to countries in which the Internet is actually censored to a substantial degree. In contrast, the present study indicates that censorship attitude is also a significant factor in countries in which the Internet is not visibly censored. This result may be considered as not very surprising because unrestricted freedom of speech and a completely uncontrolled computermediated communication through SNS has facilitated the emergence of some negative phenomena, such as online hate speech (Kaspar et al. 2017), extensive online firestorms (Pfeffer et al. 2014), and fake news (Allcott and Gentzkow 2017). The present results indicate that censorship seems to be tolerated (or even desired) as far as it helps to maintain or restore a decent communication and information space. Kou et al. (2017) have reported similar results for Chinese internet users. However, the central question is to what extent internet censorship is acceptable. In this context, it might be an interesting side note that the current debate about upload filters to regulate EU copyright (cf. Nordemann 2019) goes hand in hand with a fundamental risk of content censorship emphasized by opponents of the corresponding copyright reform.

\section{Limitations}

Finally, we want to highlight some limitations of the present study and associated prospects for future research.

First, researchers should be aware of the usual drawbacks of self-report methods as applied in the present study. Especially the controversial topic of censorship could elicit a bias in participants' response behavior because extreme responses might be considered not socially desirable. Given that the average censorship endorsement was $M=2.54$ ( $S D=$ 0.75 ) in the present online study, this bias cannot be ruled out. However, as computer-administered surveys trigger more reporting of socially sensitive behaviors and issues (Gnambs and Kaspar 2015), the online survey applied in the present study may have weakened this problem. In any case, a direct analysis of people's true information seeking behavior remains open, but such a research is actually a challenging task because the different facets of information seeking and its various nuances in reality require a profound observation methodology.

Second, at the beginning of this article, we stated that the variety of information types offered by Facebook comes along with different forms of users' information seeking strategies. We must specify that this constellation is basically true but not 
always met in reality. The variety of information is sometimes reduced as echo chambers can emerge due to users' own seeking behavior (Del Vicario et al. 2016) or prioritized information is selectively assigned to the users' individual news feed by Facebook's algorithms. This limitation does not generally jeopardize the present results, but it is important to keep in mind that the information seeking strategies examined here may be differently prioritized in different internet communities or across individual users.

Third, the present cross-sectional study was limited to correlational analyses between user attributes and information seeking, which means that conclusions about causality are prohibited. This calls for experimental or longitudinal studies. Moreover, the consideration of potential mediators (e.g., sense of security) and moderators (e.g., fear of missing out) would give more detailed insights into the cognitive and affective processes modulating information seeking behavior. Thereby, the breadth of the construct "information seeking on Facebook" must be considered. The present study showed that the relation between users' attributes and information seeking on Facebook varied across the different behavioral strategies. In this context, future studies are needed in order to validate the proposed internal structure of the concept (Asghar 2015).

Fourth, when interpreting the present results, the reader should bear in mind that all conclusions only pertain to Facebook users. For example, the positive correlation between age and information seeking behavior does not mean that older people have a stronger tendency to get their information from Facebook than younger people. It rather means that if older people use Facebook, they use it in order to search for information more strongly than younger people do.

Fifth, the effect sizes observed were rather small. However, for a better interpretation of this effect size, we want to point out that it is, inter alia, in the range of relevant effects of violent and prosocial video game exposure on behavior (Greitemeyer and Mügge 2014). We also assume that a substantial part of the inter-individual variance in users' information seeking behavior on Facebook cannot be explained by relatively time-invariant user attributes but by social determinants (e.g., social influence by peers) and individual user experiences. Nevertheless, we might speculate that the positive relation between censorship endorsement and information seeking behavior on Facebook increases when investigating specific user communities that are confronted with offending content to a larger degree, whereas the correlation might be strong but negative in societies that already actively bypass internet censorship in order to get access to information (Yang and Liu 2014). However, as these societies also seem to endorse censored information when it comes to offending content or false information (Kou et al. 2017), Facebook and other SNS must find an appropriate balance between filtering offending and false content (including options for users to report such content) and remaining a space of relatively uncensored and more complete information. Hence, the generalizability of the present results regarding censorship endorsement to other populations remains open. Further, we observed an imbalance of male and female participants in the present study that probably derived from the snowball sampling method applied. The link to the online study was distributed through several mailing lists of German universities and on Facebook. The gender ratio may reflect self-selection processes that could have affected (restricted) the variance of the data. This is not a trivial point, because the positive relation found between censorship endorsement and information seeking on Facebook might be limited to a group of (mostly female) users who expect a gratification of their needs only if Facebook is maintained a decent communication and information space.

Finally, inter-individual differences are also conceivable in light of the relation between personality characteristics (including traits and demographic properties) and information seeking behavior on Facebook. In general and in the sense of UGA, the present results signal that SNS should have a strong focus on inter-individual differences in information seeking behavior. As a consequence, it might be desirable if users of SNS were able to personalize their information seeking process, but without promoting echo chambers. This might facilitate individual need gratification by media use. For example, highly extraverted users might prefer to explore the full information spectrum, while users low in extraversion might prefer the exploitation of specific domains.

Author Contributions K. Kaspar and M. Müller-Jensen developed the study concept. K. Kaspar and M. Müller-Jensen contributed to the study design. Data collection was performed by M. Müller-Jensen. The data analysis and interpretation was performed by K. Kaspar and M. MüllerJensen. K. Kaspar wrote and revised the manuscript. M. Müller-Jensen approved the manuscript for submission.

\section{Compliance with Ethical Standards}

Conflict of Interests On behalf of all authors, the corresponding author states that there is no conflict of interest.

Ethics Statement All procedures performed in the study were in accordance with the ethical guidelines of the German Psychological Society (DGPs) and with the 1964 Helsinki declaration. According to the guidelines of the German Research Association, no ethical approval was needed because the research did not pose any threats or risks to the respondents, it was not associated with high physical or emotional stress, and the respondents were informed about the objectives of the study (http://www. dfg.de/foerderung/faq/geistes_sozialwissenschaften/index.html). At the beginning of the study, participants were informed that the data of this study will be used for research purposes only and that all data are collected anonymously. Thus, no identifying information was collected and completion of the survey was considered to indicate consent. 
Participants who prematurely stopped the survey were not included in the analyses and all of their data were deleted from the dataset.

Open Access This article is distributed under the terms of the Creative Commons Attribution 4.0 International License (http:// creativecommons.org/licenses/by/4.0/), which permits unrestricted use, distribution, and reproduction in any medium, provided you give appropriate credit to the original author(s) and the source, provide a link to the Creative Commons license, and indicate if changes were made.

\section{References}

Allcott, H., \& Gentzkow, M. (2017). Social media and fake news in the 2016 election. Journal of Economic Perspectives, 31, 211-236.

Asghar, H. M. (2015). Measuring information seeking through Facebook: Scale development and initial evidence of Information Seeking in Facebook Scale (ISFS). Computers in Human Behavior, 52, 259 270.

Bamman, D., O'Connor, B., \& Smith, N. (2012). Censorship and deletion practices in Chinese social media. First Monday, 17. https://doi.org/ 10.5210/fm.v17i3.3943.

Bertot, J. C., Jaeger, P. T., \& Grimes, J. M. (2010). Using ICTs to create a culture of transparency: E-government and social media as openness and anti-corruption tools for societies. Government Information Quarterly, 27, 264-271.

Chen, G. M. (2014). Revisiting the social enhancement hypothesis: Extroversion indirectly predicts number of Facebook friends operating through Facebook usage. Computers in Human Behavior, 39, 263-269.

Costa, P. T., Jr., \& McCrae, R. R. (1988). From catalog to classification: Murray's needs and the five-factor model. Journal of Personality and Social Psychology, 55, 258-265.

Das, S., \& Kramer, A. (2013). Self-censorship on Facebook. In Seventh international AAAI conference on weblogs and social media, 120 127

Del Vicario, M., Vivaldo, G., Bessi, A., Zollo, F., Scala, A., Caldarelli, G., \& Quattrociocchi, W. (2016). Echo chambers: Emotional contagion and group polarization on facebook. Scientific Reports, 6, 37825.

Dohle, M., \& Bernhard, U. (2014). Presumed online media influence and support for censorship: Results from a survey among German parliamentarians. International Journal of Public Opinion Research, 26, 256-268.

Facebook (2019). Facebook's mission. Retrieved 13.06.2019 from https:// www.facebook.com/pg/facebook/about/?ref=page internal.

Feiler, D. C., \& Kleinbaum, A. M. (2015). Popularity, similarity, and the network extraversion bias. Psychological Science, 27, 1-11.

Gnambs, T., \& Kaspar, K. (2015). Disclosure of sensitive behaviors across self-administered survey modes: A meta-analysis. Behavior Research Methods, 47, 1237-1259.

Gosling, S. D., Augustine, A. A., Vazire, S., Holtzman, N., \& Gaddis, S. (2011). Manifestations of personality in online social networks: Self-reported Facebook-related behaviors and observable profile information. Cyberpsychology, Behavior and Social Networking, 14, 483-488.

Greitemeyer, T., \& Mügge, D. O. (2014). Video games do affect social outcomes: A meta-analytic review of the effects of violent and prosocial video game play. Personality and Social Psychology Bulletin, 40, 578-589.

Halder, S., Roy, A., \& Chakraborty, P. K. (2017). The influence of personality traits on information seeking behaviour of students. Malaysian Journal of Library \& Information Science, 15, 41-53.
Hayes, M., van Stolk-Cooke, K., \& Muench, F. (2015). Understanding Facebook use and the psychological affects of use across generations. Computers in Human Behavior, 49, 507-511.

Hense, R., \& Wright, C. (1992). The development of the attitudes toward censorship Questionnaire1. Journal of Applied Social Psychology, $22,1666-1675$.

Hoffmann, C. P., \& Lutz, C. (2017). Spiral of silence 2.0: Political selfcensorship among young facebook users. In Proceedings of the 8th International Conference on Social Media \& Society, Article No. 10. New York: ACM.

Joinson, A. N. (2008). Looking at, looking up or keeping up with people? Motives and use of Facebook. Proceedings of the SIGCHI conference on human factors in computing systems, 1027-1036.

Kaspar, K., Gräßer, L., Riffi, A. (2017). Online Hate Speech Perspektiven auf eine neue Form des Hasses. Schriftenreihe zur digitalen Gesellschaft NRW [Online hate speech - Perspectives on a new form of hate. Publication series of the digital society NRW]. Munich: kopead.

Katz, E., Blumler, J. G., \& Gurevitch, M. (1973). Uses and gratifications research. The Public Opinion Quarterly, 37, 509-523.

Kircaburun, K., Alhabash, S., Tosuntaş, Ș. B., \& Griffiths, M. D. (2018). Uses and gratifications of problematic social media use among university students: A simultaneous examination of the big five of personality traits, social media platforms, and social media use motives. International Journal of Mental Health and Addiction, online first, 1-23.

Kou Y., Semaan B., \& Nardi B. (2017). A Confucian look at internet censorship in China. In R. Bernhaupt, G. Dalvi, A. Joshi, D. K. Balkrishan, J. O’Neill, \& M. Winckler (Eds.), Human-computer interaction - INTERACT 2017. Cham: Springer.

Kuo, T., \& Tang, H. L. (2014). Relationships among personality traits, Facebook usages, and leisure activities-a case of Taiwanese college students. Computers in Human Behavior, 31, 13-19.

Kwon, K. H., Moon, S. I., \& Stefanone, M. A. (2015). Unspeaking on Facebook? Testing network effects on self-censorship of political expressions in social network sites. Quality \& Quantity, 49, 1417 1435.

Lambe, J. L. (2002). Dimensions of censorship: Reconceptualizing public willingness to censor. Communication Law \& Policy, 7, 187-235.

Lambe, J. L. (2004). Who wants to censor pornography and hate speech? Mass Communication \& Society, 7, 279-299.

Lin, J. S., Lee, Y. I., Jin, Y., \& Gilbreath, B. (2017). Personality traits, motivations, and emotional consequences of social media usage. Cyberpsychology, Behavior and Social Networking, 20, 615-623.

Lucas, R. E., Le, K., \& Dyrenforth, P. S. (2008). Explaining the extraversion/positive affect relation: Sociability cannot account for extraverts' greater happiness. Journal of Personality, 76, 385-414.

Madsen, V. T., \& Verhoeven, J. W. (2016). Self-censorship on internal social media: A case study of coworker communication behavior in a Danish bank. International Journal of Strategic Communication, 10, 387-409.

Matzler, K., Bidmon, S., \& Grabner-Kräuter, S. (2006). Individual determinants of brand affect: The role of the personality traits of extraversion and openness to experience. Journal of Product \& Brand Management, 15, 427-434.

Ng, A. H., Kermani, M. S., \& Lalonde, R. N. (2019). Cultural differences in psychological reactance: Responding to social media censorship. Current Psychology, online first, 1-10.

Nordemann, A. (2019). Upload filters and the EU copyright reform. International Review of Intellectual Property and Competition Law, 50, 275-277.

Park, N., Kee, K. F., \& Valenzuela, S. (2009). Being immersed in social networking environment: Facebook groups, uses and gratifications, and social outcomes. Cyberpsychology \& Behavior, 12, 729-733. 
Pfeffer, J., Zorbach, T., \& Carley, K. M. (2014). Understanding online firestorms: Negative word-of-mouth dynamics in social media networks. Journal of Marketing Communications, 20, 117-128.

Quan-Haase, A., \& Young, A. L. (2010). Uses and gratifications of social media: A comparison of Facebook and instant messaging. Bulletin of Science, Technology \& Society, 30, 350-361.

Quercia, D., Lambiotte, R., Stillwell, D., Kosinski, M., \& Crowcroft, J. (2012). The personality of popular Facebook users. Proceedings of the ACM 2012 conference on computer supported cooperative work, 955-964.

Rammstedt, B., \& John, O. P. (2007). Measuring personality in one minute or less: A 10-item short version of the big five inventory in English and German. Journal of Research in Personality, 41, 203 212

Rayburn, J. D., \& Palmgreen, P. (1984). Merging uses and gratifications and expectancy-value theory. Communication Research, 11, 537562

Rojas, H., Shah, D. V., \& Faber, R. J. (1996). For the good of others: Censorship and the third-person effect. International Journal of Public Opinion Research, 8, 163-186.

Rubin, A. M. (2009). Uses and gratifications: An evolving perspective of media effects. In R. L. Nabi \& M. B. Oliver (Eds.), The SAGE handbook of media processes and effects (pp. 147-159). Thousand Oaks: Sage Publications.

Ruggiero, T. E. (2000). Uses and gratifications theory in the 21st century. Mass Communication \& Society, 3, 3-37.

Seidman, G. (2013). Self-presentation and belonging on Facebook: How personality influences social media use and motivations. Personality and Individual Differences, 54, 402-407.

Shane-Simpson, C., Manago, A., Gaggi, N., \& Gillespie-Lynch, K. (2018). Why do college students prefer Facebook, Twitter, or Instagram? Site affordances, tensions between privacy and self-expression, and implications for social capital. Computers in Human Behavior, 86, 276-288.

Sheldon, P. (2008). The relationship between unwillingness-tocommunicate and students' Facebook use. Journal of Media Psychology, 20, 67-75.

Shen, J., Brdiczka, O., \& Liu, J. (2015). A study of Facebook behavior: What does it tell about your neuroticism and extraversion? Computers in Human Behavior, 45, 32-38.

Skues, J. L., Williams, B., \& Wise, L. (2012). The effects of personality traits, self-esteem, loneliness, and narcissism on Facebook use among university students. Computers in Human Behavior, 28, 2414-2419.
Sleeper, M., Balebako, R., Das, S., McConahy, A. L., Wiese, J., \& Cranor, L. F. (2013). The post that wasn't: Exploring selfcensorship on Facebook. Proceedings of the 2013 conference on computer supported cooperative work, 793-802.

Smock, A. D., Ellison, N. B., Lampe, C., \& Wohn, D. Y. (2011). Facebook as a toolkit: A uses and gratification approach to unbundling feature use. Computers in Human Behavior, 27, 23222329.

Sundar, S. S., \& Limperos, A. M. (2013). Uses and grats 2.0: New gratifications for new media. Journal of Broadcasting \& Electronic Media, 57, 504-525.

Tsao, W. C., \& Chang, H. R. (2010). Exploring the impact of personality traits on online shopping behavior. African Journal of Business Management, 4, 1800-1812.

Tuten, T. L., \& Bosnjak, M. (2001). Understanding differences in web usage: The role of need for cognition and the five factor model of personality. Social Behavior and Personality: An International Journal, 29, 391-398.

Urista, M. A., Dong, Q., \& Day, K. D. (2009). Explaining why young adults use MySpace and Facebook through uses and gratifications theory. Human Communication, 12, 215-229.

Wang, J. L., Jackson, L. A., Wang, H. Z., \& Gaskin, J. (2015). Predicting social networking site (SNS) use: Personality, attitudes, motivation and internet self-efficacy. Personality and Individual Differences, $80,119-124$.

Warren, A. M., Jaafar, N. I., \& Sulaiman, A. (2016). Youth civic engagement behavior on Facebook: A comparison of findings from Malaysia and Indonesia. Journal of Global Information Technology Management, 19, 128-142.

Whiting, A., \& Williams, D. (2013). Why people use social media: A uses and gratifications approach. Qualitative Market Research: An International Journal, 16, 362-369.

Wilson, T. D. (2000). Human information behavior. Informing Science, 3 , $49-56$.

Wilson, K., Fornasier, S., \& White, K. M. (2010). Psychological predictors of young adults' use of social networking sites. Cyberpsychology, Behavior and Social Networking, 13, 173-177.

Yang, Q., \& Liu, Y. (2014). What's on the other side of the great firewall? Chinese web users' motivations for bypassing the internet censorship. Computers in Human Behavior, 37, 249-257.

Publisher's note Springer Nature remains neutral with regard to jurisdictional claims in published maps and institutional affiliations. 